\title{
Rosiglitazone enhances neovascularization in diabetic rat ischemic hindlimb model
}

\author{
Majid Khazaei, Ensieh Salehi
}

\begin{abstract}
Background. There is increasing evidence that peroxisome proliferator-activated receptors (PPARs) may be involved in the regulation of angiogenesis. In this study, we examined whether rosiglitazone, a PPARy agonist, can restore angiogenesis in a rat hindlimb ischemia model of diabetes.

Methods. Male wistar rats were divided into four groups ( $n=6$ each): control, diabetic and control and diabetic rats who received rosiglitazone ( $8 \mathrm{mg} / \mathrm{kg} /$ day). Diabetes was induced by streptozotocin ( $55 \mathrm{mg} / \mathrm{kg}$; ip). After 21 days, serum concentrations of nitric oxide (NO), vascular endothelial growth factor (VEGF) and soluble VEGF receptor-2 (VEGFR-2) were measured and neovascularization in ischemic legs was evaluated by immunohistochemistry.

Results. Capillary density and capillary/fiber ratio in hindlimb ischemia of diabetic animals were significantly lower than the control group $(P<0.05)$. Rosiglitazone significantly restored neovascularization in diabetic animals $(P<0.05)$.

Conclusions. rosiglitazone enhances neovascularization in diabetic ischemic skeletal muscle and could be considered for treatment of peripheral artery disease in diabetic subjects.
\end{abstract}

Key words: diabetes, rosiglitzone, angiogenesis, hindlimb ischemia

Received: September 9, 2011; Accepted with revision: April 25, 2012; Available online: June 14, 2012 http://dx.doi.org/10.5507/bp.2012.052

Department of Physiology, Isfahan University of Medical Sciences, Isfahan, Iran Corresponding author: Majid Khazaei , e-mail:khazaei@med.mui.ac.ir

\section{INTRODUCTION}

Type 2 diabetes is a major cause of morbidity and mortality in advanced societies. Cardiovascular disease is responsible for up to $80 \%$ of death in diabetic subjects ${ }^{1}$. Some of the long-term complications of diabetes are associated with impaired angiogenesis which can result in severe organ damage ${ }^{2}$. Angiogenesis is defined as sprouting of blood vessels from preexisting ones and is considered a physiological response to tissue ischemia ${ }^{3,4}$. Hypoxia is the main stimulus for angiogenesis ${ }^{4}$. Thus, angiogenic therapy is a novel approach for improving tissue perfusion in diabetic patients with reduced regional organ perfusion ${ }^{5,6}$.

Peroxisome proliferator-activated receptors (PPARs) are ligand-activated transcription factors that have three nuclear receptor isoforms, PPAR $\alpha, \operatorname{PPAR} \delta$ and PPAR $\gamma$ (ref. ${ }^{7}$ ). Rosiglitazone is a PPARy agonist that belongs to a new class of insulin sensitizers, used clinically in the management of diabetes ${ }^{8}$. PPAR $y$ is expressed in endothelial and vascular smooth muscle cells ${ }^{9}$. It is indicated that PPARy ligands not only have beneficial effects on endothelial function ${ }^{10}$, the amelioration of hyperlipidemia and hyperglycemia ${ }^{11}$, but also, upregulate angiogenic factors such as endothelial nitric oxide (NO) synthase and vascular endothelial growth factor (VEGF) expression in vascular smooth muscle cells ${ }^{12}$. In recent years, there is increasing evidence that PPARs might be involved in regulation of physiological and pathological angiogenesis? ${ }^{7}$. Since peripheral artery disease is a major complication of diabetes, in this study, we test the hypothesis that rosiglitazone can improve skeletal muscle angiogenesis in diabetic and control rats in hindlimb ischemia model.

\section{MATERIALS AND METHODS}

\section{Animals}

Ten week old male wistar rats weighing between 180$230 \mathrm{~g}$ were provided by the Pasteur Institute of Iran. The animals were randomly divided into two groups: diabetic and control. Experimental diabetes was induced by a single intraperitoneal injection of streptozotocin $(55 \mathrm{mg} / \mathrm{kg})$ dissolved in $0.9 \%$ saline. Control rats received the same volume of $0.9 \%$ saline. After $48 \mathrm{~h}$, blood samples were taken and the animals with blood glucose concentration higher than $16.7 \mathrm{mmol} / 1$ were considered diabetic ${ }^{13}$. Then, all rats were randomly divided into 4 groups as follows:

Group 1: control rats received vehicle.

Group2: control rats received rosiglitazone $(8 \mathrm{mg} / \mathrm{kg} /$ day) by gavage ${ }^{14}$.

Group3: diabetic rats received vehicle.

Group4: diabetic rats received rosiglitazone $(8 \mathrm{mg} /$ $\mathrm{kg} /$ day) by gavage.

The treatments were started one day after induction of hindlimb ischemia and lasted for 21 days. All experimental procedures were approved by the ethics committee of the authors' institution. 


\section{Rat hind limb ischemic model}

All rats were anaesthetized with ketamine $(75 \mathrm{mg} / \mathrm{kg})$ and xylazine $(7.5 \mathrm{mg} / \mathrm{kg})$, intraperitoneally. Unilateral hindlimb ischemia was induced as previously described ${ }^{15}$. In brief, the left legs were shaved and locally disinfected. Through a small incision, the left femoral artery was isolated. The proximal and distal portions of the femoral artery and distal portion of saphenous artery with side branches were ligated and excised. Subsequently, the skin was closed with 3-0 silk surgical suture. Then, the animals were returned to their cages.

\section{Capillary density analysis}

For capillary density measurement, the ischemic gasterocnemious muscles were dissected. After overnight fixation at $10 \%$ formalin, they were embedded in paraffin and cut with $5 \mu \mathrm{m}$ thickness. Then, the sections were deparaffinized and incubated with a rat-monoclonal antibody directed against mouse CD31 (Abcam Co.). Finally, capillary density was measured at $400 \times$ in ten different fields from each tissue preparation and determined as the number of CD31 positive cells per $\mathrm{mm}^{2}$. To avoid overestimate or underestimate of capillary density because of muscle atrophy or interstitial edema, capillary/muscle fiber ratio was also expressed.

\section{Measurement of plasma parameters}

After $12 \mathrm{~h}$ fasting, blood samples were taken from retroorbital space before and at the end of experiment. Blood samples were centrifuged with $10000 \mathrm{rpm}$ for $15 \mathrm{~min}$ to obtain serum triglycerides (TG), High-density lipoprotein cholesterol (HDL-C), Total cholesterol (TC) and Lowdensity lipoprotein cholesterol (LDL-C), glucose and insulin concentrations with commercially available kits.

\section{Measurement of serum NO, VEGF and VEGFR-2 concentrations}

Serum NO concentrations were measured using Griess reagent method (Promega Corp, USA). In this method, serum nitrite, the main metabolite of NO, was measured. The limit of detection is $2.5 \mu \mathrm{M}$. Serum VEGF and VEGFR-2 concentrations were measured by Enzymelinked Immunosorbent assay using available reagents and recombinant standards (R\&D systems, Minneapolis, USA). The minimum sensitivity of VEGF and VEGFR-2 assays are $3.9 \mathrm{pg} / \mathrm{ml}$ and $0.027 \mathrm{ng} / \mathrm{ml}$, respectively.

\section{Statistical analysis}

All data are expressed as mean $\pm \mathrm{SE}$. One way ANOVA tests using tukey's test were performed for comparison of data between groups. Paired t-test was used for comparison of paired data. A $P$ value less than 0.05 was considered statistically significant.

\section{RESULTS}

\section{Plasma parameters}

As shown in Table 1, the plasma level of TG was significantly reduced and serum HDL-C increased in control rats treated with rosiglitazone $(P<0.05)$. In diabetic groups, rosiglitazone also reduced serum TG and increased serum HDL-C concentrations $(P<0.05)$. Blood glucose levels were higher than $16.7 \mathrm{mmol} / 1$ in diabetic rats throughout the study and rosiglitazone administration did not alter the blood glucose level or serum insulin concentrations compared to control $(P>0.05)$ (data not shown).

\section{Evaluation of serum angiogenic factors}

Fig. 1. illustrates serum nitrite concentrations on day 21 after operation. Diabetic animals had lower serum nitrite concentration than control $(P=0.08)$. Rosiglitazone did not change serum nitrite concentration in control or diabetic animals $(P>0.05)$. Serum VEGF and VEGFR-2 concentrations were not different between control and diabetic animals $(P>0.05)$. . There were no significant differences in serum VEGF and VEGFR-2 concentrations between rosiglitazone-treated and non-treated groups $(P>0.05)$ (Fig. 2A and B).

\section{Evaluation of neovascularization}

Neovascularization was evaluated as capillary density (CD31-positive cells) per $\mathrm{mm}^{2}$ and number of capillaries per muscle fiber ratio. Neovascularization was significantly impaired in hindlimb ischemia of diabetic animals com-

Table 1. Serum lipid profile before and after study in experimental groups.

\begin{tabular}{|c|c|c|c|c|c|c|c|c|}
\hline \multirow[t]{2}{*}{ Groups } & \multicolumn{2}{|c|}{$\begin{array}{l}\text { Total Cholesterol } \\
\qquad(\mathrm{mg} / \mathrm{dl})\end{array}$} & \multicolumn{2}{|c|}{$\begin{array}{l}\text { Triglyceride } \\
(\mathrm{mg} / \mathrm{dl})\end{array}$} & \multicolumn{2}{|c|}{$\begin{array}{l}\text { HDL-C } \\
(\mathrm{mg} / \mathrm{dl})\end{array}$} & \multicolumn{2}{|c|}{$\begin{array}{l}\text { LDL-C } \\
(\mathrm{mg} / \mathrm{dl})\end{array}$} \\
\hline & Before & After & Before & After & Before & After & Before & After \\
\hline Control & $66.00 \pm 6.79$ & $84.40 \pm 8.74$ & $93.16 \pm 6.72$ & $73.40 \pm 5.88$ & $28.33 \pm 4.19$ & $44.66 \pm 5.01 *$ & $25.56 \pm 1.94$ & $28.52 \pm 3.66$ \\
\hline $\begin{array}{l}\text { Control+ } \\
\text { Rosiglitazone }\end{array}$ & $63.8 \pm 5.16$ & $53.6 \pm 6.93$ & $86.8 \pm 6.56$ & $45.6 \pm 6.12 *$ & $24.8 \pm 5.13$ & $47.00 \pm 3.06^{*}$ & $19.64 \pm 2.29$ & $10.20 \pm 0.01$ \\
\hline Diabetic & $70.33 \pm 5.44$ & $72.25 \pm 7.06$ & $81.80 \pm 15.02$ & $71.25 \pm 12.37$ & $26.00 \pm 3.55$ & $33.40 \pm 2.76^{*}$ & $19.63 \pm 2.44$ & $20.76 \pm 2.56$ \\
\hline $\begin{array}{l}\text { Diabetic }+ \\
\text { Rosiglitazone }\end{array}$ & $66.6 \pm 4.85$ & $62.2 \pm 19.33$ & $91.8 \pm 4.59$ & $68.50 \pm 4.74 *$ & $28.40 \pm 3.84$ & $42.20 \pm 8.56$ & $21.24 \pm 1.90$ & $29.60 \pm 14.8$ \\
\hline
\end{tabular}




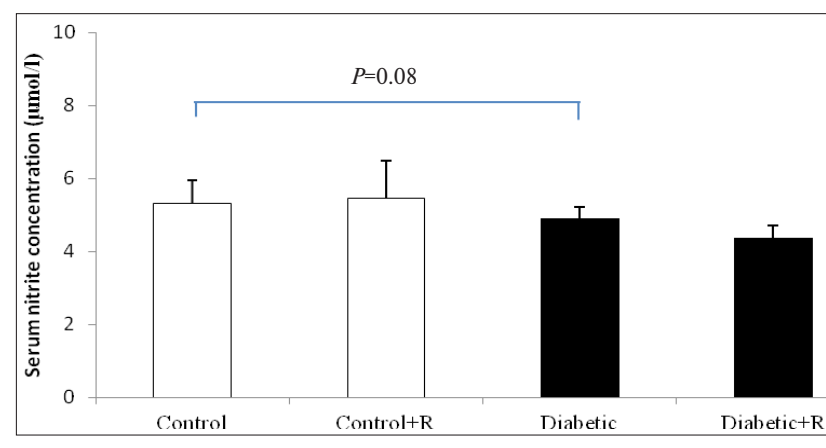

Fig. 1. Effect of rosiglitazone $(\mathrm{R})$ on serum nitrite concentration ( $\mu \mathrm{mol} / \mathrm{lit}$.$) in experimental groups. Data are shown as mean$ \pm SE, $n=6$ per group.

pared to control and rosiglitazone significantly restored capillary density and capillary/fiber ratio in the ischemic leg of diabetic rats toward control level (Fig. 3A and B). Some photographs of histological sections stained with rat-monoclonal antibody directed against murine CD31 are illustrated in Fig. 4.
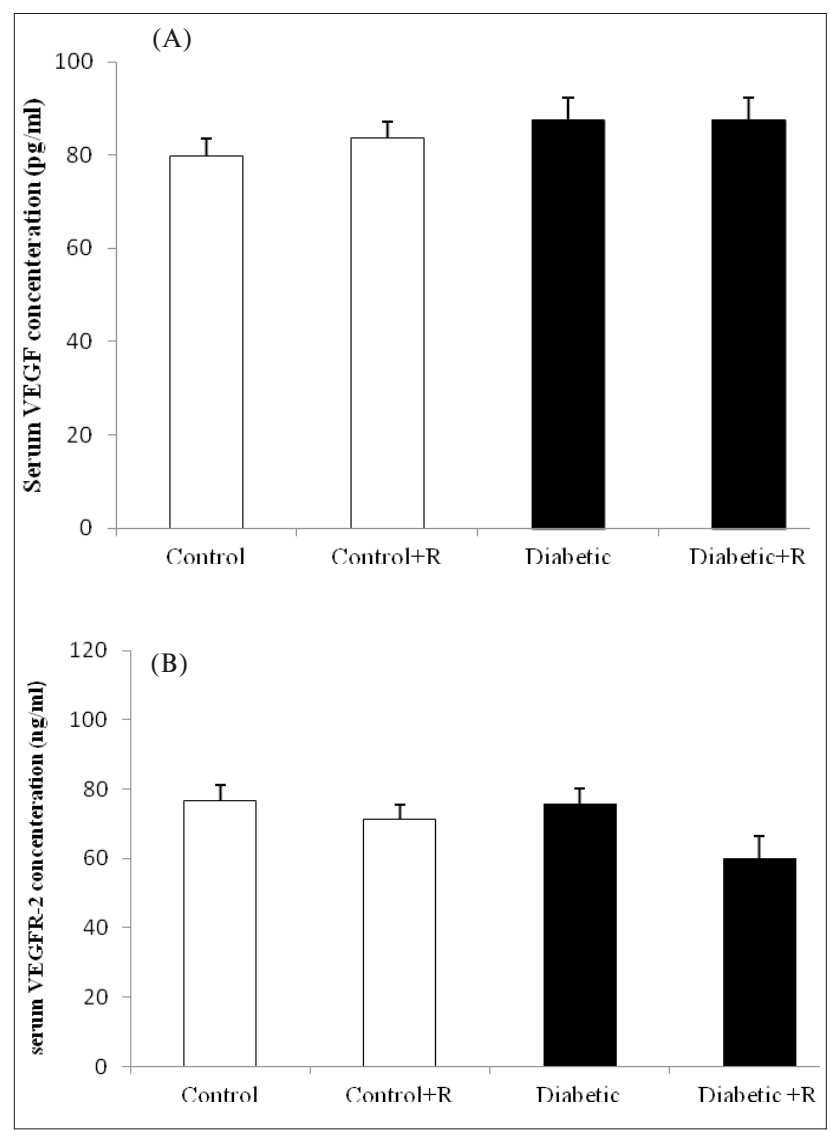

Fig. 2. Effect of rosiglitazone (R) on serum VEGF (A) and VEGFR-2 (B) concentrations. Data are shown as mean \pm SE, $\mathrm{n}=6$ per group.

\section{DISCUSSION}

In this study, we investigated the role of rosiglitazone, a PPAR $\gamma$ agonist, on angiogenesis in hindlimb ischemia in diabetic and control rats. Our data illustrated that diabetes is associated with reduced angiogenesis in ischemic skeletal muscle and rosiglitazone administration restored neovascularization in hindlimb ischemia of diabetic animals.

Rosiglitazone is a drug from thiazolidindiones (TZDs) that is not only used for improvement of insulin resistance in diabetic patients but also safeguards diabetic patients from cardiovascular events ${ }^{16}$. In the present study, we found that rosiglitazone improved serum HDL and lowered TG concentration in control and diabetic rats, however, it did not change serum insulin or glucose concentrations. In this study, we used normal rodent chow, not high-fat diet, however, our findings are in agreement with previous studies which showed that activation of PPAR $\gamma$ lowered plasma triglyceride levels and increased plasma HDL ( ref. $^{17}$ ). However, a study on cholesterol-fed rabbits revealed that rosiglitazone significantly reduced aortic atherosclerosis without modifying the plasma levels of glucose, insulin or lipid profile ${ }^{18}$.

It is believed that PPARs are involved during the angiogenesis process ${ }^{7}$. In this study, we found that angiogenesis in hindlimb ischemia of diabetic animals was

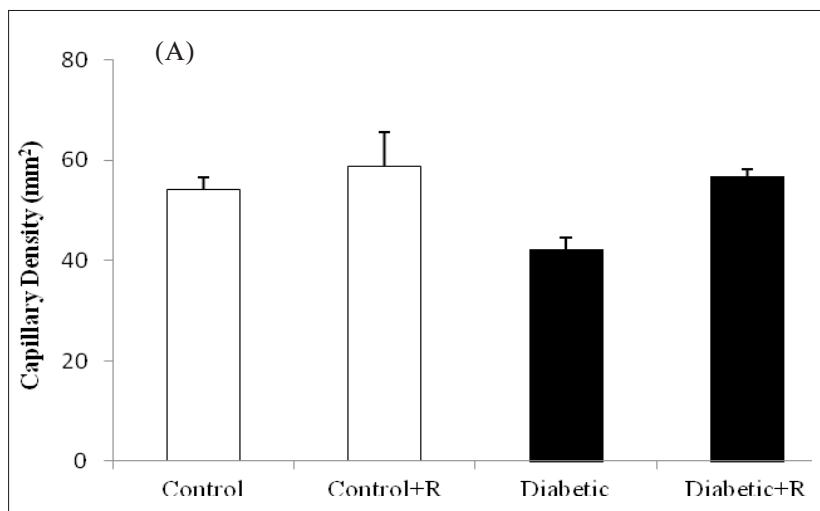

(B)

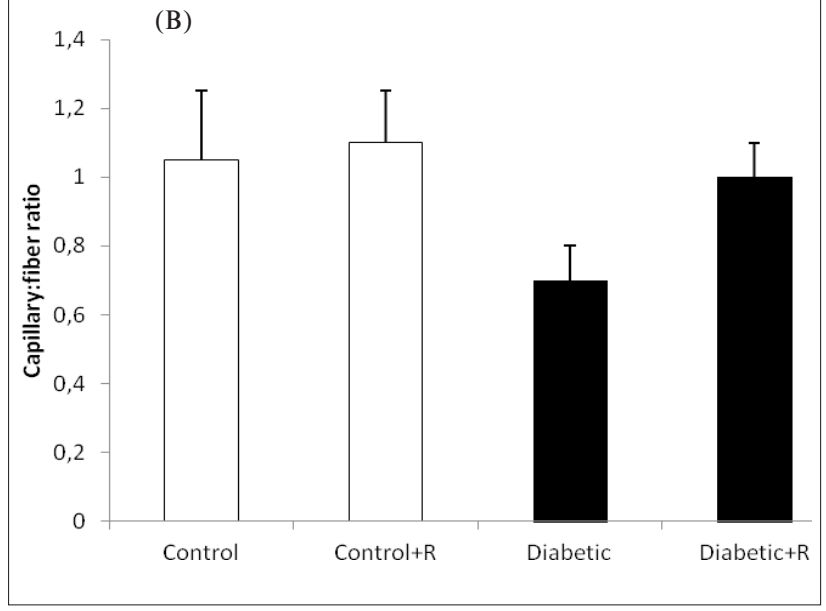

Fig. 3. Capillary density (A) and capillary/fiber ratio (B) in hindlimb ischemia. Data are shown as Mean \pm SE, $n=6$ per group. *: $P<0.05$ compare to other groups. 

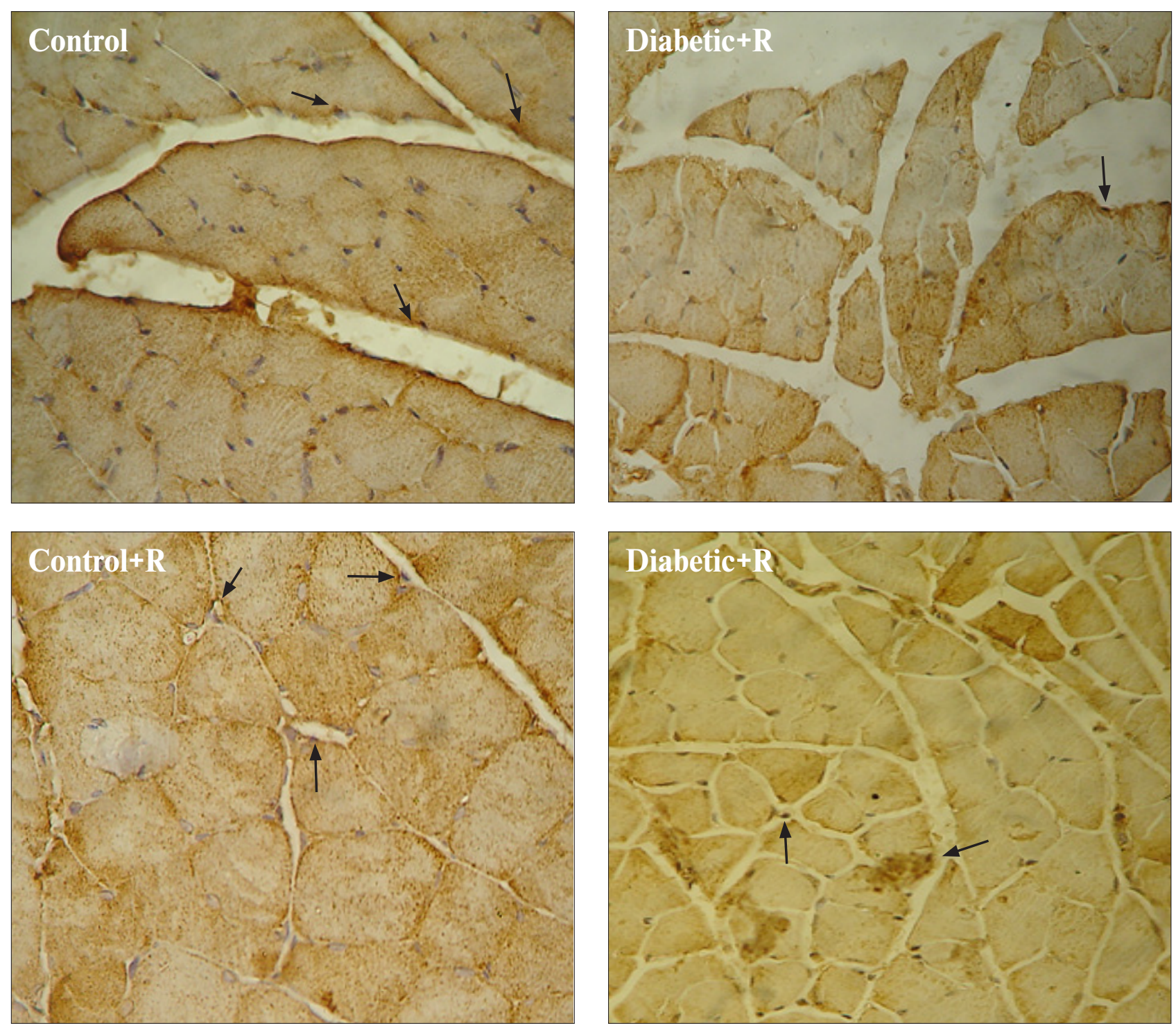

Fig. 4. Representative images of immunohistochemical staining $(\times 400)$ with anti-CD31 monoclonal antibody in ischemic skeletal muscles. Arrows indicate CD31-positive cells. R: rosiglitazone.

impaired compared to control. In addition, serum NO concentration in diabetic animals was lower than control. Enhanced angiogenesis has an important role in some complications of diabetes including diabetic retinopathy and nephropathy, on the other hand, reduced angiogenesis which is related to lower arteriogenesis and poor growth of collateral artery has an important role in cardiovascular diseases in diabetes ${ }^{2,19}$. NO not only enhances angiogenesis, but also, other angiogenic growth factors exert their angiogenic response through increasing NO production ${ }^{20}$. Reduced NO bioavailability in diabetic subjects has been reported in several studies ${ }^{21-23}$. Suppression of endothelial NO synthase (eNOS) expression and its activity $^{24}$, overproduction of superoxide ${ }^{25}$ and activation of protein kinase $\mathrm{C}$ ( ref. $^{23}$ ) during high-glucose concentration are possible mechanisms for lower NO availability in diabetic subjects. VEGF is another angiogenic factor in a variety of in vivo models ${ }^{26}$. VEGFR-2 is also an effector of proangiogenic signaling in the angiogenesis process ${ }^{27}$.
In the present study, we found no significant differences in serum VEGF and VEGFR-2 concentrations between control and diabetic animals. It is suggested that without considering the serum VEGF level, the VEGF signaling pathway is impaired during diabetes which is considered as VEGF resistance ${ }^{28,29}$. Therefore, it is possible that reduced serum NO concentration may be responsible for lower neovascularization in hindlimb ischemic tissue of diabetic animals.

We also found that rosiglitazone restored neovascularization in the ischemic leg of diabetic animals. The angiogenic abilities of PPAR $\gamma$ agonists have been broadly examined; however, the results are contradictory. Studies in different angiogenesis models revealed that activation of PPAR $\gamma$ upregulates receptor of antiangiogenic factor thrombospondin in chorioallantoic membrane $\mathrm{e}^{30}$, inhibits bFGF- and VEGF-mediated angiogenesis, suppresses VEGF-induced angiogenesis in rat cornea model ${ }^{31}$, and inhibits tumor growth angiogenesis and metastasis ${ }^{32}$. 
In agreement with our results, a recent study on KKAy mice indicated that pioglitazone administration restored ischemia-induced angiogenesis ${ }^{15}$. In that study, Huang et al. used pioglitazone as the PPAR $\gamma$ agonist. It was shown that pioglitazone is a partial PPAR $\gamma$ agonist and considered as a less potent ligand, whereas, rosiglitazone appears to be a pure PPARy agonist with high affinity to receptor ${ }^{7}$. Another study demonstrated that PPAR $\gamma$ agonists increase angiogenesis after focal cerebral ischemia ${ }^{33}$. Rosiglitazone also has a myocardial protective role during ischemia/reperfusion injury ${ }^{34}$. Several mechanisms have been suggested for the angiogenic role of PPAR $\gamma$ agonists. Huang et al. suggested that activation of eNOS is the main mechanism for enhanced angiogenesis ${ }^{15}$. In the present study, we found that serum NO, VEGF and VEGFR-2 concentrations did not alter after rosiglitazone treatment. Increase in number of endothelial progenitor cells is suggested as another mechanism for enhanced angiogenesis of PPAR $\gamma$ activation $^{35}$. Therefore, it is possible that the effect of PPAR $\gamma$ agonists on angiogenesis in pathological or ischemic condition is different.

In conclusions, diabetes is associated with impaired angiogenesis in ischemic skeletal muscle and rosiglitazone restored neovascularization in diabetic animals. Since diabetes is one of the most important risk factors for the development of peripheral vascular disease, it seems that rosiglitazone can be considered for treatment of peripheral artery disease in diabetic subjects. Further studies are needed to clarify the exact role and mechanisms of PPAR $\gamma$ agonists on physiological and pathological angiogenesis.

\section{ACKNOWLEDGMENTS}

This study was supported by a grant from Isfahan University of Medical Sciences (grant no: 188138). We thank B. Rashidi for technical assistance.

\section{REFERENCES}

1. Kirpichnikov D, Sowers JR. Diabetes mellitus and diabetes-associated vascular disease. Trends Endocrinol Metab 2001;12:225-30.

2. Martin A, Komada MR, Sane DC. Abnormal angiogenesis in diabetes mellitus. Med Res Rev 2003;23:117-45.

3. Pandya NM. Angiogenesis a new target for future therapy. Vascul Pharmacol 2006;44(5):265-74.

4. Karamysheva AF. Mechanisms of angiogenesis. Biochemistry (Mosc) 2008;73:751-62.

5. Tomanek RJ, Schatteman GC. Angiogenesis: new insights and therapeutic potential. Anat Rec 2000;261:126-35.

6. Griffioen AW, Molema G. Angiogenesis: potentials for pharmacologic intervention in the treatment of cancer, cardiovascular diseases, and chronic inflammation. Pharmacol Rev 2000;52:237-68.

7. Biscetti F, Straface G, Pitocco D, Zaccardi F, Ghirlanda G, Flex A. Peroxisome proliferator-activated receptors and angiogenesis. Nutr Metab Cardiovasc Dis 2009;19:751-9.

8. Staels B, Fruchart JC. Therapeutic roles of peroxisome proliferatoractivated receptor agonists. Diabetes 2005;54:2460-70.

9. Staels B, Koenig W, Habib A, Merval R, Lebret M, Torra IP, Delerive P, Fadel A, Chinetti G, Fruchart JC, Najib J, Maclouf J, Tedgui A. Activation of human aortic smooth-muscle cells is inhibited by PPARalpha but not by PPARgamma activators. Nature 1998;393:79093.
10. Sidhu JS, Cowan D, Kaski JC. The effects of rosiglitazone, a peroxisome proliferator-activated receptor-gamma agonist, on markers of endothelial cell activation, C-reactive protein, and fibrinogen levels in non-diabetic coronary artery disease patients. J Am Coll Cardiol 2003;42:1757-63.

11. Biscetti F, Gaetani E, Flex A, Aprahamian T, Hopkins T, Straface G, Pecorini G, Stigliano E, Smith RC, Angelini F, Castellot JJ, Pola, R. Selective activation of peroxisome proliferator-activated receptor (PPAR)alpha and PPAR gamma induces neoangiogenesis through a vascular endothelial growth factor-dependent mechanism. Diabetes 2008;57:1394-04

12. Yamakawa K, Hosoi M, Koyama H, Tanaka S, Fukumoto $S$, Morii $H$, Nishizawa Y. Peroxisome proliferator-activated receptor-gamma agonists increase vascular endothelial growth factor expression in human vascular smooth muscle cells. Biochem Biophys Res Commun 2000;271:571-74

13. Taniyama $Y$, Morishita $R$, Aoki M, Nakagami H, Yamamoto $K$, Yamazak K, Matsumoto K, Nakamura T, KanedaY. Therapeutic angiogenesis induced by human hepatocyte growth factor gene in rat and rabbit hindlimb ischemia models: preclinical study for treatment of peripheral arterial disease. Gene Ther 2001;8:181-89.

14. Wang CH, Ciliberti N, Li SH, Szmitko PE, Weisel RD, Fedak PW, AlOmran M, Cherng WJ, Li RK, Stanford WL, Verma S. Rosiglitazone facilitates angiogenic progenitor cell differentiation toward endothelial lineage: a new paradigm in glitazone pleiotropy. Circulation 2004;109:1392-400.

15. Huang $P H$, Sata $M$, Nishimatsu $H$, Sumi $M$, Hirata $Y$, Nagai R. Pioglitazone ameliorates endothelial dysfunction and restores ischemia-induced angiogenesis in diabetic mice. Biomed Pharmacother 2008;62:46-52.

16. Campia U, Matuskey LA, Panza JA. Peroxisome proliferator-activated receptor-gamma activation with pioglitazone improves endothelium-dependent dilation in nondiabetic patients with major cardiovascular risk factors. Circulation 2006;113: 867-75.

17. Edvardsson $U$, Bergstrom $M$, Alexandersson $M$, Bamberg K, Ljung $B$, Dahllof B. Rosiglitazone (BRL49653), a PPARgamma-selective agonist, causes peroxisome proliferator-like liver effects in obese mice. J Lipid Res 1999;40:1177-84.

18. Zhao S, Zhang C, Lin Y, Yang P, Yu Q, Chu Y, Fan J, Liu E. The effects of rosiglitazone on aortic atherosclerosis of cholesterol-fed rabbits. Thromb Res 2008;123:281-87.

19. Waltenberger J. VEGF resistance as a molecular basis to explain the angiogenesis paradox in diabetes mellitus. Biochem Soc Trans 2009;37:1167-70.

20. Hood JD, Meininger CJ, Ziche M, Granger HJ. VEGF upregulates ecNOS message, protein, and NO production in human endothelial cells. Am J Physiol 1998;274:H1054-H58.

21. Lash JM, Nase GP, Bohlen HG. Acute hyperglycemia depresses arteriolar NO formation in skeletal muscle. Am J Physiol 1999;277:H1513-H20.

22. Brodsky SV, Morrishow AM, Dharia N, Gross SS, Goligorsky MS. Glucose scavenging of nitric oxide. Am J Physiol Renal Physiol 2001;280:F480-F86.

23. Bohlen HG, Nase GP. Arteriolar nitric oxide concentration is decreased during hyperglycemia-induced betall PKC activation. Am J Physiol Heart Circ Physiol 2001;280:H621-H27.

24. Ding Y, Vaziri ND, Coulson R. Effects of simulated hyperglycemia, insulin, and glucagon on endothelial nitric oxide synthase expression. Am J Physiol Endocrinol Metab 2000;279:E11-E17.

25. Bagi Z, Toth $E$, Koller A. Microvascular dysfunction after transient high glucose is caused by superoxide-dependent reduction in the bioavailability of $\mathrm{NO}$ and $\mathrm{BH}(4)$. Am J Physiol Heart Circ Physiol 2004;287:H626-H33.

26. Olsson AK, Dimberg A, Kreuger J.VEGF receptor signalling - in control of vascular function. Nat Rev Mol Cell Biol 2006;7:359-71.

27. Wu FT, Stefanini MO, Mac GF, Kontos CD, Annex BH, Popel AS. A systems biology perspective on SVEGFR1: its biological function, pathogenic role and therapeutic use. J Cell Mol Med 2010;14:528-52.

28. Waltenberger J. VEGF resistance as a molecular basis to explain the angiogenesis paradox in diabetes mellitus. Biochem Soc Trans 2009;37:1167-70.

29. Sasso FC, Torella D, Carbonara O, Ellison G.M, Torella M, Scardone M, Marra C, Nasti R, Marfella R, Cozzolino D, Indolfi C, Cotrufo M, Torella R, Salvatore T. Increased vascular endothelial growth factor 
expression but impaired vascular endothelial growth factor receptor signaling in the myocardium of type 2 diabetic patients with chronic coronary heart disease. J Am Coll Cardiol 2005;46:827-34.

30. Murata T, He S, Hangai M, Ishibashi T, Xi XP, Kim S, Hsueh WA, Ryan SJ, Law RE, Hinton DR. Peroxisome proliferator-activated receptor-gamma ligands inhibit choroidal neovascularization. Invest Ophthalmol Vis Sci 2000;41:2309-17.

31. Sarayba MA, Li L, Tungsiripat T, Liu NH, Sweet PM, Patel AJ, Osann KE, Chittiboyina A, Benson SC, Pershadsingh HA, Chuck RS. Inhibition of corneal neovascularization by a peroxisome proliferator-activated receptor-gamma ligand. Exp Eye Res 2005; 80:435-42.

32. Panigrahy $D$, Singer $S$, Shen L.Q, Butterfield CE, Freedman DA, Chen EJ, Moses MA, Kilroy S, Duensing S, Fletcher C, Fletcher JA, Hlatky L, Hahnfeldt P, Folkman J, Kaipainen A. PPARgamma ligands inhibit primary tumor growth and metastasis by inhibiting angiogenesis. J Clin Invest 2002;110:923-32.
33. Chu K, Lee ST, Koo JS, Jung KH, Kim EH, Sinn DI, Kim JM, Ko SY, Kim SJ, Song EC, Kim M, Roh JK. Peroxisome proliferator-activated receptorgamma-agonist, rosiglitazone, promotes angiogenesis after focal cerebral ischemia. Brain Res 2006;1093:208-18.

34. Yue TI TL, Chen J, Bao W, Narayanan PK, Bril A, Jiang W, Lysko PG, Gu JL, Boyce R, Zimmerman DM, Hart TK, Buckingham RE, Ohlstein $\mathrm{EH}$. In vivo myocardial protection from ischemia/reperfusion injury by the peroxisome proliferator-activated receptor-gamma agonist rosiglitazone. Circulation 2001;104:2588-94.

35. Pistrosch F, Herbrig K, Oelschlaegel U, Richter S, Passauer J, Fischer $S$, Gross P. PPARgamma-agonist rosiglitazone increases number and migratory activity of cultured endothelial progenitor cells. Atherosclerosis. 2005;183:163-7.

\section{LETTER TO THE EDITOR}

Rosiglitazone belongs to the thiazolidinedione class of compounds that exhibit agonist activity on PPAR-gamma (peroxisome proliferator-activated receptor gamma). These drugs enhance the sensitivity of tissues to the effects of endogenous insulin. Rosiglitazone was registered in the European Union as Avandia in July 2000. As an oral antidiabetic drug, it was used in the treatment of patients with type 2 diabetes mellitus. Rosiglitazone was served as a second-line drug where other treatments had failed. In June 2010, studies were published describing the adverse effects of this antidiabetic drug especially on the cardiovascular system ${ }^{1,2}$. Based on this information, the European Medicines Agency recommended the withdrawal of rosiglitazone in the EU member states.

The paper, entitled "Rosiglitazone enhances neovascularization in diabetic rat ischemic hind limb model" describes a new effect of rosiglitazone on angiogenesis in an animal model (rat). The results of this communica- tion are interesting and may contribute to the future use of rosiglitazone in for new indications. This is of course a question for further experiments and studies.

\section{REFFEERENCES}

1. Graham DJ, Ouellet-Hellstrom R, MaCurdy TE, Ali F, Sholley C, Worrall C, Kelman JA. Risk of acute myocardial infarction, stroke, heart failure, and death in elderly Medicare patients treated with rosiglitazone or pioglitazone. JAMA 2010;304(4):411-18.

2. Nissen SE Wolski K. Rosiglitazone revisited: An updated meta analysis of risk for myocardial infarction and cardiovascular mortality. Arch Intern Med 2010;170(14):1191-1201.

Rostislav Vecera Department of Pharmacology, Faculty of Medicine and Dentistry, Palacky University Olomouc, Czech Republic 